\title{
Left Ventricular Hypertrophy by ECG
}

\section{Finding}

National Cancer Institute

\section{Source}

National Cancer Institute. Left Ventricular Hypertrophy by ECG Finding. NCI Thesaurus.

Code C71076.

An electrocardiographic finding suggestive of a hypertrophied left ventricle, characterized by large QRS amplitudes and secondary findings of left atrial enlargement, left axis deviation, or typical pattern of ST depression and T wave inversion. (CDISC) 